\title{
BMJ Open Sexual orientation-related disparities in employment, health insurance, healthcare access and health-related quality of life: a cohort study of US male and female adolescents and young adults
}

\author{
Brittany M Charlton, ${ }^{1,2,3,4}$ Allegra R Gordon, ${ }^{1,2}$ Sari L Reisner, ${ }^{2,4,5,6}$ \\ Vishnudas Sarda, ${ }^{1}$ Mihail Samnaliev, ${ }^{1,2}$ S Bryn Austin ${ }^{1,2,3,7}$
}

To cite: Charlton BM, Gordon AR, Reisner SL, et al. Sexual orientation-related disparities in employment, health insurance, healthcare access and health-related quality of life: a cohort study of US male and female adolescents and young adults. BMJ Open 2018;8:e020418. doi:10.1136/ bmjopen-2017-020418

- Prepublication history for this paper is available online To view these files, please visit the journal online (http://dx.doi. org/10.1136/bmjopen-2017020418).

An abstract of this work was presented at the Society for Adolescent Health and Medicine Annual Meeting and GLMA Annual Conference on LGBT Health.

Received 9 November 2017 Revised 27 February 2018 Accepted 4 May 2018
Check for updates

For numbered affiliations see end of article.

Correspondence to Dr Brittany M Charlton; bcharlton@mail.harvard.edu

\section{ABSTRACT}

Objective To investigate sexual orientation-related disparities in employment and healthcare, including potential contributions to health-related quality of life (HRQL).

Setting Growing Up Today Study, a USA-based Iongitudinal cohort that began in 1996; predominantly composed of participants who are white and of middle-tohigh socioeconomic positions.

Participants 9914 participants 18-32 years old at the most recent follow-up questionnaire.

Primary outcome measure In 2013, participants reported if, in the last year, they had been unemployed, uninsured or lacked healthcare access (routine physical exam). Participants completed the EQ-5D-5L, a validated, preference-weighted measurement of HRQL. After adjusting for potential confounders, we used sex-stratified, log-binomial models to calculate the association of sexual orientation with employment, health insurance and healthcare access, while examining if these variables attenuated the sexual orientation-related HRQL disparities. Results Sexual minority women and men were about twice as likely as their respective heterosexual counterparts to have been unemployed and uninsured. For example, the risk ratio $(95 \% \mathrm{Cl})$ of uninsured bisexual women was 3.76 (2.42 to 5.85) and of unemployed mostly heterosexual men was 1.82 (1.30 to 2.54). Routine physical examination was not different across sexual orientation groups $(p>0.05)$. All sexual minority subgroups had worse HRQL than heterosexuals $(p<0.05)$ across the five EQ-5D-5L dimensions (mobility, self-care, usual activities, pain/discomfort and anxiety/depression). Controlling for employment and health insurance did not substantially attenuate the existing sexual orientationrelated HRQL disparities.

Conclusions Research on sexual orientation-related disparities in employment and healthcare has often been limited to comparisons between cohabitating different-sex and same-sex adult couples, overlooking sexual minority subgroups (eg, bisexuals vs lesbians), non-cohabitating populations and young people. Less is known about sexual
Strengths and limitations of this study

- The cohort has predominantly high social status, so while the findings can examine sexual orientation-related differences, they may underestimate the prevalence of unemployment, lack of health insurance, lack of healthcare access and poor health-related quality of life (HRQL) compared with other populations (eg, low social status, elderly).

- There may be other factors that mediate the sexual orientation-related HRQL disparities, including bullying victimisation, social status and others.

- Data were cross-sectional and limited on some of our variables, such as health insurance and healthcare access.

- The study includes a large sample drawn from young adults living across the USA.

- This is the first study to examine the disparities across HRQL domains and to evaluate the role of additional factors including employment, health insurance and healthcare access.

orientation-related disparities in HRQL including potential contributions from employment and healthcare. The current study documents that disparities in employment, health insurance and various HRQL dimensions are pervasive across sexual minority subgroups, noncohabitating couples and youth in families of middle-tohigh socioeconomic positions.

\section{INTRODUCTION}

Nearly half of all sexual minorities (eg, lesbian, gay and bisexual individuals) report employment discrimination in their lifetime. ${ }^{1}$ Discrimination, along with other social and economic barriers, can lead to unemployment, and subsequently lack of health insurance and healthcare access. All of these 
factors may contribute to poor health-related quality of life (HRQL), which is a critical measure of health status. Comparing HRQL across different subpopulations can highlight disparities, as well as help to evaluate the cost-effectiveness of policies or programmes that reduce such disparities. $^{2}$

Previous research has documented that, compared with heterosexuals, sexual minorities are more likely to be unemployed, lack health insurance and lack healthcare access. ${ }^{3-13}$ However, these data are often limited to comparisons between cohabitating different-sex couples and same-sex adult couples, which precludes examination of differences in any other aspects such as among sexual minority subgroups (eg, bisexuals vs lesbians), non-cohabitating groups or young people. A few previous studies have also revealed that sexual minorities, on average, have worse quality of life than heterosexuals. ${ }^{14-19}$ But most of these data depend on limited measures of quality of life, including measures such as the Medical Outcomes Study 36-Item Short-Form Health Survey, which does not explicitly assess HRQL, including its multiple dimensions (eg, pain/discomfort, anxiety/depression). Additionally, few of these studies have examined potential mediators of the sexual orientation-related disparities in HRQL.

Documenting such disparities can provide policymakers with evidence to inform legislation that can lessen health inequities. For example, over half of the states across the USA currently have no employment non-discrimination law covering sexual orientation ${ }^{20}$. Using research to document the downstream consequences of unemploymenthealth insurance, healthcare access and HRQL-can aid policymakers in crafting the necessary legal changes to lessen these inequities, such as federal employment non-discrimination laws. Therefore, the goal of this study was to leverage data from a USA-based longitudinal cohort of adolescents and young adults (ages 18-32) to examine sexual orientation-related disparities in employment, health insurance and healthcare access, while evaluating their contributions to HRQL disparities.

\section{METHODS}

\section{Study population}

For the last 20 years, questionnaire data have been collected annually in the Growing Up Today Study (GUTS) from the female and male offspring of the Nurses' Health Study 2 (NHS2) participants. The first wave of GUTS participants (GUTS1) was enrolled in 1996, when they were 9-14 years of age, and another wave aged 9-16years old was enrolled in 2004 (GUTS2), making the entire cohort 18-32 years of age at the last questionnaire wave in 2013. We originally sent questionnaires to GUTS1 and GUTS2 in alternating years, but since 2013 we have combined GUTS1 and GUTS2 into a single annual questionnaire. Participants' race/ethnicity is primarily white, and most of their families report a middle-to-high household income (64\% of participants had an annual household income during their childhood of $\geq \$ 75000$ ).
The current analysis was limited to GUTS participants who reported their sexual orientation and information on measures of unemployment, health insurance, healthcare access and HRQL between baseline and at the end of follow-up in $2013(\mathrm{n}=9914)$.

\section{Measures}

\section{Sexual orientation}

Detailed information about sexual orientation has been repeatedly collected in GUTS1 and GUTS2 using an item adapted from the Minnesota Adolescent Health Survey, ${ }^{21}$ which asks about feelings of attraction and identity. The item reads 'Which of the following best describes your feelings?' with the following response options: completely heterosexual (attracted to persons of the opposite sex), mostly heterosexual, bisexual (equally attracted to men and women), mostly homosexual, completely homosexual (gay/lesbian, attracted to persons of the same sex) and not sure.

Sexual orientation groups were modelled using the 2013 questionnaire data (the same questionnaire year as the latest outcome) as follows: completely heterosexual (reference group), mostly heterosexual, bisexual and lesbian/gay (made up from the mostly homosexual and completely homosexual groups). Missing data were limited and imputed from previous questionnaire waves. Respondents endorsing 'not sure' were excluded ( $n=69)$.

\section{Unemployment}

In 2010 (GUTS1 only) and 2013, participants reported their employment status. Response options included working full time, working part-time, student, volunteering, military, unemployed/laid off/looking for work, staying at home with children/taking care of family, on maternity or family leave, and not working due to illness or disability. We categorised participants as being unemployed/not working due to illness or disability in 2013 if they provided an affirmative response to the 'unemployed/laid off/looking for work' item or the 'not working due to illness or disability' item.

\section{Lacking health insurance}

The 2013 questionnaire asked participants whether they were covered by any kind of health insurance or healthcare plan (yes; no). We categorised participants as lacking health insurance in 2013 if they reported no such coverage.

\section{Lacking healthcare access through routine physical exam}

The use of routine physical exams was measured by asking about the timing of the last routine physical exam in 2013. We categorised participants who reported their last routine physical exam occurred $>12$ months before the questionnaire completion as not having healthcare access through a routine physical exam.

Health-related quality of life

The 2013 questionnaire assessed HRQL using the EQ-5D-5L, ${ }^{22}$ which is a validated, preference-weighted 
measure. EQ-5D-5L is a standardised, generic instrument that is applicable to a wide range of health conditions and appropriate for use with adolescents and young adults. This measure can also be used to calculate quality-adjusted life years for economic analyses with USA-based population weights.

EQ-5D-5L assesses HRQL in five dimensions (mobility, self-care, usual activities, pain/discomfort and anxiety/ depression) by having participants report a dimension-specific score ( $1=$ no problems, $2=$ slight problems, $3=$ moderate problems, $4=$ severe problems and $5=$ extreme problems). Based on the EuroQol Group recommendations, ${ }^{23}$ each physical functioning dimension was dichotomised into a score of 1 being 'no problems' vs scores of $2-5$ being 'any problems'. The anxiety/depression dimension was dichotomised into scores of 1-2 being 'none or slight problems' vs scores of 3-5 being 'moderate, severe, or extreme problems', as has been done previously. ${ }^{24}$

All five dimensions were then used to create a summary HRQL index score.$^{25}$ Because EQ-5D-5L value sets are not yet available for the USA, in order to preference-weight the index score for US populations we relied on another value set to map the EQ-5D-5L responses to the previous version, the EQ-5D-3L. ${ }^{26}$ This summary results in an index score that is calibrated to reflect the degree to which different health statuses are valued in the US population overall. The index scores for the US population range from the most severe impairment on all five dimensions, termed 'worse than death' (value $=-0.109$ ), to full health (value $=1.0) .{ }^{27}$ Previous research suggests that an index score difference as small as 0.02 points can have a clinically meaningful difference. ${ }^{28}$ We also analysed the HRQL index score after dichotomising it as a score of 1 being 'full health' vs $<1$ being 'not full health'.

\section{Confounders}

Potential confounders included baseline age in years, race/ethnicity (white, another race/ethnicity), childhood socioeconomic position (annual household income from the NHS2 report in $2001(<\$ 50000, \$ 50000-\$ 74999$, $\$ 75000-\$ 99999, \geq \$ 100000)$ ), sex/gender, marital status in 2013 (married, not married), region of residence (West, Midwest, South or Northeast) and cohort (GUTS1, GUTS2). If a participant's data were missing for potential confounders, data were imputed from previous questionnaire years; if no such data were available for a participant, then multiple imputation procedures were used.

\section{Statistical analysis}

We first examined cross-sectional mean differences in employment, health insurance, healthcare access and HRQL measures across sexual orientation groups. Multivariate regression from log-binomial models was used for dichotomous outcomes to calculate risk ratios (RR) and $95 \%$ CIs. Linear regression with the robust sandwich estimator was used for continuous outcomes to calculate the betas $(\beta)$ and SEs. In order to account for sibling clusters, we estimated the variance using generalised estimating equations with a compound symmetry working correlation matrix.

We calculated the RRs of experiencing unemployment, lacking health insurance or lacking healthcare access by sexual orientation groups (referent $=$ completely heterosexual), adjusted for potential confounders. Analyses for HRQL measures followed the previously used two-step approach, ${ }^{29}{ }^{30}$ by first dichotomising the index score $(1$ vs $<1)$ and then using the continuous health index score in analyses restricted to those with lower HRQL (defined as health index scores $<1$ ). HRQL models were first adjusted for potential confounders, and then adjusted for employment, health insurance and healthcare access to explore attenuation. Previous research with this cohort $^{14}$ suggests possible effect modification of the sexual orientation and HRQL association by sex/gender but not by cohort, so all analyses were stratified by sex/gender and adjusted for cohort. Analyses were conducted using SAS V.9.3.

\section{Patient and public involvement}

The public, including patients and study participants, was not involved in setting the research question or the outcome measures, nor was the public involved in developing plans for the study design, recruitment or implementation. The GUTS research results are regularly reported to study participants, including through newsletters and other communications.

\section{RESULTS}

Of the 9914 participants in our sample, $7.5 \%$ were unemployed or not working due to illness or disability, $4.9 \%$ were uninsured, and $38.2 \%$ lacked healthcare access through a routine physical exam in the last year. As shown in table 1 , all of these outcomes varied by sexual orientation identity, with sexual minorities having more unemployment, less health insurance and less healthcare access (all $\mathrm{p}$ values $<0.01$, except among men, where healthcare access was not statistically different across sexual orientation groups). The mean HRQL index score was 0.90 for women and 0.92 for men and varied by sexual orientation identity, with sexual minorities having lower mean HRQL index scores compared with completely heterosexuals among both women and men $(\mathrm{p}<0.001)$. Within each of the five HRQL domains, sexual minority women and men were more likely than heterosexuals to report worse health ( $p$ values ranged from $<0.001$ to 0.02 , except among men, where self-care was not statistically different across sexual orientation groups).

Table 2 presents the RRs and 95\% CIs for the association between sexual orientation and the risk of being unemployed, lacking health insurance or lacking healthcare access, adjusted for potential confounders. Compared with heterosexuals, sexual minority women and men were about twice as likely as their respective heterosexual counterparts to have been unemployed and uninsured. For example, bisexual women were at a higher risk than 
Table 1 Age-standardised characteristics of a cohort of US women and men by sex/gender and sexual orientation $(n=9914)$

\begin{tabular}{|c|c|c|c|c|c|}
\hline & $\begin{array}{l}\text { Completely } \\
\text { heterosexual }\end{array}$ & $\begin{array}{l}\text { Mostly } \\
\text { heterosexual }\end{array}$ & Bisexual & Lesbian/Gay & \\
\hline Female $(n=6663)$ & $(n=5353)$ & $(n=1037)$ & $(n=159)$ & $(n=114)$ & P values* \\
\hline $\begin{array}{l}\text { Age at baselinet, mean years (SD), range: } \\
18-32\end{array}$ & $26.1(3.6)$ & $26.6(3.4)$ & $25.5(3.6)$ & $26.4(3.5)$ & $<0.001$ \\
\hline $\begin{array}{l}\text { Unemployed/not working due to illness or } \\
\text { disability in the last yearf, \% (n) }\end{array}$ & $5.9(317)$ & $10.5(109)$ & $14.5(23)$ & $10.5(12)$ & $<0.001$ \\
\hline $\begin{array}{l}\text { Uninsured (lacked health insurance) in } \\
\text { the last yearf, \% ( } n \text { ) }\end{array}$ & $3.9(208)$ & $5.7(59)$ & $13.8(22)$ & $4.4(5)$ & $<0.001$ \\
\hline $\begin{array}{l}\text { Lacked a routine physical exam in the last } \\
\text { yearł, } \%(n)\end{array}$ & $32.0(1712)$ & $36.1(374)$ & $40.3(64)$ & $37.7(43)$ & 0.01 \\
\hline \multicolumn{6}{|l|}{ HRQL§ dimensions, \% (n) } \\
\hline Mobility $\geq$ slight problems & $3.2(172)$ & $5.6(58)$ & $13.2(21)$ & $10.5(12)$ & $<0.001$ \\
\hline Self-care $\geq$ slight problems & $0.5(28)$ & $1.3(13)$ & $4.4(7)$ & $1.8(2)$ & $<0.001$ \\
\hline Usual activities $\geq$ slight problems & $5.0(267)$ & $12.3(127)$ & $20.1(32)$ & $16.7(19)$ & $<0.001$ \\
\hline Pain/discomfort $\geq$ slight problems & $26.5(1418)$ & $36.8(382)$ & $42.1(67)$ & $44.7(51)$ & $<0.001$ \\
\hline Anxiety/depression $\geq$ moderate problems & $12.3(658)$ & $22.6(234)$ & $36.5(58)$ & $29.0(33)$ & $<0.001$ \\
\hline HRQL index scoreף, mean (SD) & $0.91(0.09)$ & $0.87(0.09)$ & $0.84(0.11)$ & $0.85(0.10)$ & $<0.001$ \\
\hline Less than full health $(\mathrm{HRQL}$ index score $<1)$ & $54.6(2924)$ & $73.3(760)$ & $84.3(134)$ & $79.0(90)$ & $<0.001$ \\
\hline $\begin{array}{l}\text { HRQL index score among those with less } \\
\text { than full health, mean (SD) }\end{array}$ & $0.84(0.06)$ & $0.83(0.06)$ & $0.80(0.09)$ & $0.81(0.08)$ & $<0.001$ \\
\hline Male $(n=3251)$ & $(n=2805)$ & $(\mathrm{n}=268)$ & $(n=25)$ & $(n=153)$ & \\
\hline $\begin{array}{l}\text { Age at baselinet, mean years (SD), range: } \\
18-32\end{array}$ & $25.9(3.7)$ & $26.1(3.7)$ & $24.6(3.8)$ & $25.9(3.6)$ & 0.26 \\
\hline $\begin{array}{l}\text { Unemployed/not working due to illness or } \\
\text { disability in the last yearf, \% ( } n \text { ) }\end{array}$ & $7.8(218)$ & $15.3(41)$ & $8.0(2)$ & $11.1(17)$ & $<0.001$ \\
\hline $\begin{array}{l}\text { Uninsured (lacked health insurance) in } \\
\text { the last yearł, \% (n) }\end{array}$ & $5.2(147)$ & $9.7(26)$ & $0.0(0)$ & $11.1(17)$ & $<0.001$ \\
\hline $\begin{array}{l}\text { Lacked a routine physical exam in the last } \\
\text { yearł, } \%(n)\end{array}$ & $48.8(1369)$ & $47.8(128)$ & $36.0(9)$ & $54.9(84)$ & 0.26 \\
\hline \multicolumn{6}{|l|}{ HRQL§ dimensions, \% (n) } \\
\hline Mobility $\geq$ slight problems & $3.1(86)$ & $6.3(17)$ & $8.0(2)$ & $2.6(4)$ & 0.02 \\
\hline Self-care $\geq$ slight problems & $0.6(18)$ & $1.1(3)$ & $4.0(1)$ & $0.0(0)$ & 0.11 \\
\hline Usual activities $\geq$ slight problems & $3.8(107)$ & $10.5(28)$ & $8.0(2)$ & $5.9(9)$ & $<0.001$ \\
\hline Pain/discomfort $\geq$ slight problems & $25.4(711)$ & $38.8(104)$ & $32.0(8)$ & $24.2(37)$ & $<0.001$ \\
\hline Anxiety/depression $\geq$ moderate problems & $10.2(285)$ & $25.8(69)$ & $24.0(6)$ & $28.1(43)$ & $<0.001$ \\
\hline HRQL index score§, mean (SD) & $0.92(0.09)$ & $0.87(0.11)$ & $0.86(0.12)$ & $0.89(0.09)$ & $<0.001$ \\
\hline Less than full health ( $\mathrm{HRQL}$ index score $<1$ ) & $47.3(1329)$ & $70.2(188)$ & $76.0(19)$ & $68.0(104)$ & $<0.001$ \\
\hline $\begin{array}{l}\text { HRQL index score among those with less } \\
\text { than full health, mean (SD) }\end{array}$ & $0.84(0.06)$ & $0.82(0.08)$ & $0.82(0.11)$ & $0.84(0.06)$ & $<0.001$ \\
\hline
\end{tabular}

${ }^{*} \mathrm{P}$ values were calculated using analysis of variance for continuous variables and $\chi^{2}$ test for categorical variables (including those with a zero frequency cell such as the self-care HRQL dimension).

†Multiple imputation used in subsequent analyses for any missing covariates data. Per cent missing: race/ethnicity (1.2\%), marital status

$(0.2 \%)$, socioeconomic position (17.8\%) and geographical region $(0.1 \%)$.

$\ddagger$ As reported in 2013.

§Health-related quality of life (HRQL) measured by the EQ-5D-5L, a validated preference-weighted measure for US populations.

ПPossible scores ranged from -0.109 ('worse than death') to 1 ('full health').

heterosexual women of being uninsured (RR $3.76(95 \%$ CI 2.42 to 5.85)), and mostly heterosexual men were more likely than heterosexual men to have been unemployed (RR 1.82 (95\% CI 1.30 to 2.54)). The use of a routine physical exam was not statistically different across sexual orientation groups.

Table 3 presents the RRs and 95\% CIs for the association between sexual orientation identity and the 
Table 2 Multivariable* risk ratios of experiencing unemployment or lacking health insurance or lacking healthcare access in a cohort of US men and women by sex/gender and sexual orientation $(n=9914)$

\begin{tabular}{|c|c|c|c|c|}
\hline \multirow[b]{3}{*}{ Female $(n=6663)$} & \multicolumn{4}{|c|}{ Relative risk $(95 \% \mathrm{Cl})$} \\
\hline & $\begin{array}{l}\text { Completely } \\
\text { heterosexual }\end{array}$ & Mostly heterosexual & Bisexual & Lesbian/Gay \\
\hline & $(n=5353)$ & $(n=1037)$ & $(n=159)$ & $(n=114)$ \\
\hline $\begin{array}{l}\text { Unemployed/not working due to illness or } \\
\text { disability in the last yeart }\end{array}$ & 1.00 (ref) & 1.68 (1.35 to 2.09 ) & 2.39 (1.56 to 3.65$)$ & $1.84(1.03$ to 3.27$)$ \\
\hline $\begin{array}{l}\text { Uninsured (lacked health insurance) in } \\
\text { the last year† }\end{array}$ & 1.00 (ref) & 1.39 (1.04 to 1.86$)$ & 3.76 (2.42 to 5.85$)$ & $1.18(0.49$ to 2.88$)$ \\
\hline Male $(n=3251)$ & $(n=2805)$ & $(n=268)$ & $(n=25)$ & $(n=153)$ \\
\hline $\begin{array}{l}\text { Unemployed/not working due to illness or } \\
\text { disability in the last yeart }\end{array}$ & 1.00 (ref) & 1.82 (1.30 to 2.54$)$ & $1.00(0.25$ to 4.06$)$ & 1.49 (0.91 to 2.45$)$ \\
\hline
\end{tabular}

*Adjusted for age, race/ethnicity, childhood household income (reported by the mother in 2001), geographical region and cohort; multiple imputation used for missing covariates.

†As reported in 2013.

¥Every bisexual man reported health insurance coverage in 2013 so no risk ratio was computed.

NA, not available; ref, reference.

risk of having poorer HRQL (index score <1 vs 1 ). Model 0 demonstrates that, after accounting for potential confounders, sexual minority women and men had elevated risk of less than full health relative to completely heterosexuals. The addition of unemployment (model 1), lacking health insurance (model 2), lacking routine physical exam (model 3) or all three of these combined (model 4) did not substantially

Table 3 Multivariable* risk ratios of experiencing less than full health (HRQL index score $<1$ vs HRQL index score $=1$ ) in a cohort of US men and women by sex/gender and sexual orientation $(n=9914)$

\begin{tabular}{|c|c|c|c|c|}
\hline \multirow[b]{3}{*}{ Female $(n=6663)$} & \multicolumn{4}{|c|}{ Relative risk (95\% Cl) } \\
\hline & $\begin{array}{l}\text { Completely } \\
\text { heterosexual }\end{array}$ & $\begin{array}{l}\text { Mostly } \\
\text { heterosexual }\end{array}$ & Bisexual & Lesbian/Gay \\
\hline & $(n=5353)$ & $(n=1037)$ & $(n=159)$ & $(n=114)$ \\
\hline Model 0: sociodemographics & 1.00 (ref) & 1.33 (1.27 to 1.39$)$ & 1.53 (1.42 to 1.65$)$ & 1.42 (1.29 to 1.57$)$ \\
\hline Model 1: model 0 + unemployed & 1.00 (ref) & 1.32 (1.26 to 1.38$)$ & 1.51 (1.40 to 1.62$)$ & 1.41 (1.28 to 1.56$)$ \\
\hline Model 2: model 0 + uninsured & 1.00 (ref) & 1.32 (1.27 to 1.38$)$ & 1.50 (1.39 to 1.61$)$ & $1.42(1.29$ to 1.57$)$ \\
\hline $\begin{array}{l}\text { Model 3: model } 0+\text { lacked routine } \\
\text { physical exam }\end{array}$ & 1.00 (ref) & 1.33 (1.27 to 1.39$)$ & 1.53 (1.42 to 1.65$)$ & $1.42(1.29$ to 1.57$)$ \\
\hline $\begin{array}{l}\text { Model 4: model } 0 \text { + unemployed } \\
+ \text { uninsured + lacked routine } \\
\text { physical exam }\end{array}$ & 1.00 (ref) & 1.32 (1.26 to 1.38$)$ & 1.48 (1.37 to 1.60$)$ & 1.41 (1.28 to 1.56$)$ \\
\hline Male $(n=3251)$ & $(n=2805)$ & $(n=268)$ & $(n=25)$ & $(n=153)$ \\
\hline Model 0: sociodemographics & 1.00 (ref) & 1.46 (1.34 to 1.60$)$ & 1.62 (1.29 to 2.03$)$ & $1.43(1.27$ to 1.60$)$ \\
\hline Model 1: model 0 + unemployed & 1.00 (ref) & 1.43 (1.31 to 1.57$)$ & 1.62 (1.28 to 2.05$)$ & 1.41 (1.26 to 1.58$)$ \\
\hline Model 2: model $0+$ uninsured & 1.00 (ref) & 1.46 (1.33 to 1.59$)$ & 1.63 (1.29 to 2.04$)$ & $1.42(1.26$ to 1.59$)$ \\
\hline $\begin{array}{l}\text { Model 3: model } 0+\text { lacked routine } \\
\text { physical exam }\end{array}$ & 1.00 (ref) & 1.46 (1.34 to 1.60$)$ & 1.62 (1.29 to 2.03$)$ & 1.43 (1.27 to 1.60$)$ \\
\hline $\begin{array}{l}\text { Model } 4 \text { : model } 0 \text { + unemployed } \\
+ \text { uninsured + lacked routine } \\
\text { physical exam }\end{array}$ & 1.00 (ref) & 1.43 (1.31 to 1.56$)$ & 1.62 (1.28 to 2.05$)$ & 1.41 (1.26 to 1.58$)$ \\
\hline
\end{tabular}

*Adjusted for age, race/ethnicity, childhood household income (reported by the mother in 2001), geographical region and cohort; multiple imputation used for missing covariates.

HRQL, health-related quality of life; ref, reference. 
Table 4 Multivariable* linear associations between sexual orientation and HRQL index score in young adulthood among those who reported less than full health (score $<1)$ in a cohort of US men and women by sex/gender $(n=5547)$

\begin{tabular}{|c|c|c|c|c|c|c|}
\hline \multirow[b]{3}{*}{ Female $(n=3908)$} & \multicolumn{5}{|l|}{$\beta$ (SE) } & \multirow[b]{3}{*}{$P$ values } \\
\hline & Mostly heterosexual & & Bisexual & & Lesbian/Gay & \\
\hline & $(n=760)$ & $P$ values & $(n=134)$ & $P$ values & $(n=90)$ & \\
\hline Model 0: sociodemographics & $-0.010(0.003)$ & $<0.001$ & $-0.034(0.008)$ & $<0.001$ & $-0.026(0.008)$ & 0.002 \\
\hline $\begin{array}{l}\text { Model 1: model } \\
0+\text { unemployed }\end{array}$ & $-0.010(0.003)$ & $<0.001$ & $-0.033(0.008)$ & $<0.001$ & $-0.025(0.008)$ & 0.002 \\
\hline Model 2: model 0 + uninsured & $-0.010(0.003)$ & $<0.001$ & $-0.033(0.008)$ & $<0.001$ & $-0.026(0.008)$ & 0.002 \\
\hline $\begin{array}{l}\text { Model 3: model } \\
0+\text { lacked routine physical } \\
\text { exam }\end{array}$ & $-0.010(0.003)$ & $<0.001$ & $-0.034(0.008)$ & $<0.001$ & $-0.025(0.008)$ & 0.002 \\
\hline $\begin{array}{l}\text { Model } 4 \text { : model } \\
0+\text { unemployed } \\
+ \text { uninsured }+ \text { lacked routine } \\
\text { physical exam }\end{array}$ & $-0.009(0.003)$ & $<0.001$ & $-0.033(0.008)$ & $<0.001$ & $-0.025(0.008)$ & 0.002 \\
\hline Male $(n=1639)$ & $(n=188)$ & & $(n=19)$ & & $(n=104)$ & \\
\hline Model 0: sociodemographics & $-0.020(0.006)$ & 0.001 & $-0.021(0.025)$ & 0.40 & $-0.004(0.006)$ & 0.47 \\
\hline $\begin{array}{l}\text { Model } 1: \text { model } \\
0+\text { unemployed }\end{array}$ & $-0.019(0.006)$ & 0.002 & $-0.022(0.025)$ & 0.38 & $-0.003(0.006)$ & 0.54 \\
\hline Model 2: model 0 + uninsured & $-0.020(0.006)$ & 0.001 & $-0.022(0.025)$ & 0.38 & $-0.004(0.006)$ & 0.54 \\
\hline $\begin{array}{l}\text { Model 3: model } \\
0+\text { lacked routine physical } \\
\text { exam }\end{array}$ & $-0.020(0.006)$ & 0.001 & $-0.021(0.025)$ & 0.40 & $-0.004(0.006)$ & 0.47 \\
\hline $\begin{array}{l}\text { Model } 4 \text { : model } \\
0+\text { unemployed } \\
+ \text { uninsured + lacked routine } \\
\text { physical exam }\end{array}$ & $-0.019(0.006)$ & 0.002 & $-0.022(0.025)$ & 0.38 & $-0.003(0.006)$ & 0.58 \\
\hline
\end{tabular}

*Adjusted for age, race/ethnicity, childhood household income (reported by the mother in 2001), geographical region and cohort; multiple imputation used for any missing covariates; completely heterosexual is the reference.

attenuate the associations between sexual orientation and HRQL.

Table 4 presents the results for the multivariable linear regression of HRQL restricted to those with less than full health (index score $<1$ ). The patterns were similar to those provided in table 3 , with sexual minorities having lower HRQL compared with their completely heterosexual peers, and these relationships were not substantially attenuated after accounting for the effects of unemployment, lacking health insurance and lacking a routine physical exam.

\section{DISCUSSION}

Sexual minority women and men are more likely than heterosexuals to have been unemployed and uninsured in early adulthood. Within each of the five HRQL dimensions, sexual minorities were also more likely than their heterosexual peers to report worse health. These disparities are pervasive in a US population that predominantly holds high social status with regard to race/ethnicity and socioeconomic position.

The existing literature on sexual orientation-related employment disparities primarily focuses on its contribution to more poverty among sexual minorities compared with heterosexuals. ${ }^{4-6} 13$ Sexual minority women, as well as sexual minority people of colour, appear to be especially vulnerable to poverty. Badgett and Schneebaum ${ }^{5}$ documented that policies to reduce wage gaps between heterosexual men and various sexual minority groups, including women and people of colour, can significantly reduce poverty. Although there is limited research on sexual orientation and employment status, data from the 2010 American Community Survey compare male same-sex couples and female same-sex couples with different-sex couples, all of which are cohabitating. These data reveal that cohabitating women in same-sex couples are more likely than women or men in cohabitating different-sex couples to be unemployed or not in the labour force. An estimated $40.4 \%$ of cohabitating women in same-sex couples were unemployed or not in the workforce compared with $21.8 \%$ of cohabitating men in same-sex relationships and $25.5 \%$ of cohabitating women and men in different-sex couples. Women in same-sex couples benefit the least from employment as a way out of poverty because even among employed groups, women are at the highest risk of being in poverty. ${ }^{6}$ The 
findings of the present study support these data, revealing higher unemployment among sexual minority women compared with heterosexual women. We also found larger employment disparities among sexual minority men, possibly because our sample was not restricted to cohabitating participants.

Other studies have documented sexual orientation-related disparities in health insurance and healthcare access. For example, one of the largest nationally representative samples recently revealed that women in same-sex relationships were significantly less likely than women in different-sex relationships to have health insurance or to have had a check-up in the last year. Men in same-sex relationships in that sample were also less likely than men in different-sex relationships to have health insurance but more likely to have a check-up in the last year. ${ }^{7}$ The present study supports most of the same patterns and a similar magnitude of health insurance and healthcare access disparities. A number of other studies document these same health insurance and healthcare access disparities using a cohabitating-based approach, ${ }^{3911} 12$ and these results have also been repeated in other non-cohabitating samples as well. ${ }^{4810}$ However, many of these studies use samples that have limited statistical power, collapse sexual minority subgroups (eg, lesbians and bisexuals) and are restricted to older adults who are in cohabitating relationships. The present study overcomes those challenges with a large sample allowing for improved statistical power and stratified sexual minority subgroups during late adolescent and early adulthood.

Our findings support the previous research that has identified lower HRQL among sexual minorities ${ }^{14-19}$ using other quality of life measures. ${ }^{31-35}$ Bisexual and lesbian women in the USA-based NHS2 cohort had lower HRQL scores than heterosexuals. ${ }^{15}$ Certain sexual minority groups, including bisexual women and heterosexual men with same-sex partners, had lower HRQL scores than their heterosexual peers without same-sex partners in the state-based Representative California Quality of Life Survey. ${ }^{16}$ Men who have sex with men in a Swedish sample had lower psychosocial HRQL scores than their heterosexual peers. ${ }^{17}$ Other studies among college students have also identified lower quality of life among sexual minority women and men, including one sample from Nigeria ${ }^{18}$ and another from Cuba, Norway, India and South Africa. ${ }^{19}$ Another study from a USA-based sample in Washington state was restricted to sexual minorities, and therefore lacked a heterosexual comparison group; in this sample, young bisexual women had worse HRQL than their lesbian peers, but these patterns reversed during mid-life when lesbians had worse HRQL. ${ }^{36}$ Research on sexual orientation-related HRQL disparities using the EQ-5D-5L is scarce, but this measure was used in two recent publications, one from the GUTS cohort ${ }^{14}$ and another based on a sample in Barcelona, Spain. ${ }^{37}$ The current findings support these two publications' findings that sexual minorities participants presented worse HRQL than heterosexuals, and the current study also adds new insights. For example, the previous GUTS publication did not include estimates of the different HRQL dimensions-nor the contribution from employment and healthcare-and the Spanish sample was not large enough to examine sexual minority subgroups.

In addition to the differences observed in the current study comparing sexual minorities with heterosexuals, there were also notable differences comparing men and women, as well as across sexual orientation subgroups. Male participants were more likely than female participants to have lacked a physical exam within the last year, but less likely than female participants to have experienced pain/discomfort (one of the five HRQL dimensions). These patterns align with existing literature on men being less likely than women to seek healthcare, ${ }^{38}$ and the prevalence of pain that women experience compared with men. ${ }^{39}$ While the primary analyses examined sexual minority subgroups in relation to the completely heterosexual group, some striking patterns emerged comparing sexual minority subgroups with one another. For example, bisexual women were the most likely to have been uninsured $(13.8 \%)$ compared with completely heterosexual $(3.9 \%)$ women, as well as compared with mostly heterosexual $(5.7 \%)$ and lesbian $(4.4 \%)$ women $(p<0.001)$. These findings align with the literature documenting that bisexuals often experience some of the highest burdens of adverse health, even compared with other sexual minority subgroups. ${ }^{40}$

The GUTS cohort is made up of children of the NHS2 participants, so the results in this sample may not generalise to other populations; this cohort is predominantly of white race/ethnicity, their mothers are all nurses and the annual household income of the majority of the participants during their childhood was $\geq \$ 75000$. Given this high social status, our estimates may underestimate the prevalence of unemployment, lack of health insurance, lack of healthcare access and poor HRQL. However, the fact that these disparities are pervasive in a cohort that predominantly holds high social status is striking. While our focus was on employment, health insurance and healthcare access, there may be other factors that mediate the sexual orientation-related HRQL disparities, including bullying victimisation, social status and others. ${ }^{14}$ The lack of explanation in these disparities by HRQL in this cohort may be due to the participants' young age. Future research should explore how employment and healthcare may interact with age to drive worse HRQL as people age. Data were cross-sectional and limited on some of our variables such as health insurance and healthcare access. Future longitudinal studies could explore more detailed types of health insurance coverage as well as other measurements of healthcare access.

This study has a number of strengths, including the large sample drawn from young adults living across the USA. Building off the recently published data of sexual orientation-related disparities of HRQL index scores, ${ }^{14}$ this is the first study to examine these disparities across 
HRQL domains and sexual minority subgroups while also evaluating the role of additional factors including employment, health insurance and healthcare access. Using the EQ-5D-5L to measure HRQL allows the findings to be incorporated into cost-effectiveness research, which can inform public policy decisions.

These sexual orientation-related disparities in employment and health insurance in a population with high social status highlight the ubiquity of sexual orientation inequities in the employment and healthcare systems. The US Supreme Court's recent expansion of marriage rights to adults nationwide in same-sex relationships should lessen some of the sexual orientation-related disparities in health insurance. However, the adverse effects of previous bans are likely to persist. ${ }^{41}{ }^{42}$ Additionally, 28 states across the USA currently have no employment non-discrimination law covering sexual orientation-3 of these states have laws preventing the passage or enforcement of local non-discrimination laws. ${ }^{20}$ Until all people, regardless of sexual orientation, are treated equally in the eyes of the law, including with non-discrimination laws protecting employment as well as housing, public accommodations and credit/lending, sexual orientation-related health disparities will persist.

\section{Author affiliations \\ ${ }^{1}$ Division of Adolescent/Young Adult Medicine, Boston Children's Hospital, Boston, Massachusetts, USA \\ ${ }^{2}$ Department of Pediatrics, Harvard Medical School, Boston, Massachusetts, USA ${ }^{3}$ Channing Division of Network Medicine, Department of Medicine, Brigham and Women's Hospital, Boston, Massachusetts, USA \\ ${ }^{4}$ Department of Epidemiology, Harvard TH Chan School of Public Health, Boston, Massachusetts, USA \\ ${ }^{5}$ Division of General Pediatrics, Boston Children's Hospital, Boston, Massachusetts, USA \\ ${ }^{6}$ The Fenway Institute, Fenway Health, Boston, Massachusetts, USA \\ ${ }^{7}$ Department of Social and Behavioral Sciences, Harvard TH Chan School of Public Health, Boston, Massachusetts, USA}

Contributors BMC conceptualised the project, supervised the analyses, and led the development and writing of the article. SBA supervised the data collection and, along with ARG, SLR and MS, aided in the interpretation of data and critically reviewed the manuscript for important intellectual content. VS conducted the analyses.

Funding BMC was supported by grant F32HD084000 and SBA by R01HD057368 and R01HD066963 from the Eunice Kennedy Shriver National Institute of Child Health and Human Development, National Institutes of Health. Additional funds were provided to BMC by GLMA: Health Professionals Advancing LGBT Equality's Lesbian Health Fund and by MRSG CPHPS 130006 from the American Cancer Society. SLR was partly supported by grant CER-1403-12625 from the Patient-Centered Outcomes Research Institute.

Competing interests None declared.

Patient consent Obtained.

Ethics approval This study was approved by the Brigham and Women's Hospital Institutional Review Board.

Provenance and peer review Not commissioned; externally peer reviewed.

Data sharing statement No additional data available.

Open access This is an open access article distributed in accordance with the terms of the Creative Commons Attribution (CC BY 4.0) license, which permits others to distribute, remix, adapt and build upon this work, for commercial use, provided the original work is properly cited. See: http://creativecommons.org/ licenses/by/4.0/ (c) Article author(s) (or their employer(s) unless otherwise stated in the text of the article) 2018. All rights reserved. No commercial use is permitted unless otherwise expressly granted.

\section{REFERENCES}

1. Sears B, Mallory C. Documented Evidence of Employment Discrimination \& Its Effects on LGBT People: The Williams Institute, 2011.

2. Miller W, Robinson LA, Lawrence RS, Valuing health for regulatory cost-effectiveness analysis. Washington, D.C: National Academies Press, 2006.

3. Badgett MVL, Ash MA. Separate and unequal: the effect of unequal access to employment-based health insurance on gay, lesbian, and bisexual people. Contemp Econ Policy 2006;24:582-99.

4. Austin EL, Irwin JA. Health behaviors and health care utilization of southern lesbians. Womens Health Issues 2010;20:178-84.

5. Badgett MVL, Schneebaum A. The impact of wage equality on sexual orientation poverty gaps: The Williams Institute, 2015.

6. Badgett MVL, Durso LE, Schneebaum A. New patterns of poverty in the lesbian, gay, and bisexual community: The Williams Institute, 2013.

7. Buchmueller T, Carpenter CS. Disparities in health insurance coverage, access, and outcomes for individuals in same-sex versus different-sex relationships, 2000-2007. Am J Public Health 2010;100:489-95.

8. Diamant AL, Wold C, Spritzer K, et al. Health behaviors, health status, and access to and use of health care: a population-based study of lesbian, bisexual, and heterosexual women. Arch Fam Med 2000;9:1043-51.

9. Gonzales G, Blewett LA. National and state-specific health insurance disparities for adults in same-sex relationships. Am J Public Health 2014;104:e95-e104.

10. Gonzales G, Henning-Smith C. The affordable care act and health insurance coverage for lesbian, gay, and bisexual adults: analysis of the behavioral risk factor surveillance system. LGBT Health 2017;4:62-7.

11. Heck JE, Sell RL, Gorin SS. Health care access among individuals involved in same-sex relationships. Am J Public Health 2006;96:1111-8.

12. Pals $\mathrm{H}$, Waren $\mathrm{W}$. Winners and losers in health insurance: access and type of coverage for women in same-sex and opposite-sex partnerships. Women Health 2014;54:94-114.

13. Prokos AH, Keene JR. Poverty among cohabiting gay and lesbian, and married and cohabiting heterosexual families. J Fam Issues 2010;31:934-59.

14. Austin SB, Gordon AR, Ziyadeh NJ, et al. Stigma and health-related quality of life in sexual minorities. Am J Prev Med 2017;53:559-66. Epub ahead of print.

15. Case P, Austin SB, Hunter DJ, et al. Sexual orientation, health risk factors, and physical functioning in the Nurses' Health Study II. $J$ Womens Health 2004;13:1033-47.

16. Cochran SD, Mays VM. Physical health complaints among lesbians, gay men, and bisexual and homosexually experienced heterosexual individuals: results from the California Quality of Life Survey. Am J Public Health 2007;97:2048-55.

17. Eriksson LE, Berglund T. Health-related quality of life in homo- and bisexual men attending a sexually transmitted disease clinic in Sweden. Int J STD AIDS 2007;18:207-11.

18. Boladale M, Olakunle O, Olutayo A, et al. Sexual orientation and quality of life among students of Obafemi Awolowo University (OAU), Nigeria. Afr Health Sci 2015;15:1065-73.

19. Traeen B, Martinussen M, Vitters $ø$ J, et al. Sexual orientation and quality of life among university students from Cuba, Norway, India, and South Africa. J Homosex 2009;56:655-69.

20. Movement Advancement Project. Non-Discrimination Laws. 2017 http://www.lgbtmap.org/equality-maps/non_discrimination_laws (accessed 28 Jun 2017)

21. Remafedi G, Resnick M, Blum R, et al. Demography of sexual orientation in adolescents. Pediatrics 1992;89:714-21.

22. Johnson JA, Coons SJ. Comparison of the EQ-5D and SF-12 in an adult US sample. Qual Life Res 1998;7:155-66.

23. EuroQol Group. EQ-5D-5L. 2017 https://euroqol.org/eq-5dinstruments/eq-5d-5I-about/ (accessed 12 Jan 2017).

24. Gordon AR, Krieger N, Okechukwu CA, et al. Decrements in healthrelated quality of life associated with gender nonconformity among U.S. adolescents and young adults. Qual Life Res 2017;26:2129-38.

25. Agency for Healthcare Research and Quality. U.S. valuation of the EuroQol EQ-5 health states: research initiative in clinical economics. 
2012 http://www.ahrq.gov/professionals/clinicians-providers/ resources/rice/EQ5Dproj.html (accessed 12 Jan 2017).

26. van Hout $B$, Janssen MF, Feng $Y S$, et al. Interim scoring for the EQ5D-5L: mapping the EQ-5D-5L to EQ-5D-3L value sets. Value Health 2012;15:708-15.

27. Lubetkin El, Jia H, Franks $\mathrm{P}$, et al. Relationship among sociodemographic factors, clinical conditions, and health-related quality of life: examining the EQ-5D in the U.S. general population. Qual Life Res 2005;14:2187-96.

28. Goldsmith KA, Dyer MT, Schofield PM, et al. Relationship between the EQ-5D index and measures of clinical outcomes in selected studies of cardiovascular interventions. Health Qual Life Outcomes 2009;7:96

29. Pullenayegum EM, Tarride JE, Xie F, et al. Analysis of health utility data when some subjects attain the upper bound of 1: are Tobit and CLAD models appropriate? Value Health 2010;13:487-94.

30. Bilger M, Finkelstein EA, Kruger E, et al. The effect of weight loss on health, productivity, and medical expenditures among overweight employees. Med Care 2013;51:471-7.

31. Pavot W, Diener E. Review of the Satisfaction With Life Scale. Psychol Assess 1993;5:164-72.

32. Lyubomirsky S, Lepper HS. A measure of subjective happiness: preliminary reliability and construct validation. Soc Indic Res 1999;46:137-55

33. The World Health Organization Quality of Life Assessment (WHOQOL): development and general psychometric properties. Soc Sci Med 1998;46:1569-85.
34. Ware J, Kosinski M, Keller SD. A 12-Item Short-Form Health Survey: construction of scales and preliminary tests of reliability and validity. Med Care 1996;34:220-33.

35. Ware J. SF-36 physical and mental health summary scales: a user's manual. Boston: Health Institute New England Medical Center, 1994.

36. Fredriksen-Goldsen KI, Kim HJ, Barkan SE, et al. Disparities in health-related quality of life: a comparison of lesbians and bisexual women. Am J Public Health 2010;100:2255-61.

37. Marti-Pastor M, Perez G, German D, et al. Health-related quality of life inequalities by sexual orientation: Results from the Barcelona Health Interview Survey. PLoS One 2018;13:e0191334.

38. Galdas PM, Cheater F, Marshall P. Men and health help-seeking behaviour: literature review. J Adv Nurs 2005:49:616-23.

39. Fillingim RB, King CD, Ribeiro-Dasilva MC, et al. Sex, gender, and pain: a review of recent clinical and experimental findings. J Pain 2009;10:447-85.

40. Gorman BK, Denney JT, Dowdy H, et al. A new piece of the puzzle: sexual orientation, gender, and physical health status. Demography 2015;52:1357-82.

41. Hatzenbuehler ML, McLaughlin KA, Keyes KM, et al. The impact of institutional discrimination on psychiatric disorders in lesbian, gay, and bisexual populations: a prospective study. Am J Public Health 2010;100:452-9.

42. Hatzenbuehler ML, O'Cleirigh C, Grasso C, et al. Effect of samesex marriage laws on health care use and expenditures in sexual minority men: a quasi-natural experiment. Am J Public Health 2012;102:285-91. 